\title{
Evidence for a physiological role of prostaglandins in oviposition by the hen
}

\author{
F. Hertelendy and H. V. Biellier* \\ Departments of Medicine and Physiology, St Louis University School of Medicine, St Louis, \\ Missouri 63104, and * Department of Poultry Science, University of Missouri, Columbia, \\ Missouri 65201, U.S.A.
}

\begin{abstract}
Summary. A single oral dose of indomethacin $(25 \mathrm{mg})$ given $2-4 \mathrm{~h}$ before expected oviposition delayed oviposition by about $12 \mathrm{~h}$ and suppressed plasma PGE levels by about $90 \%$. Intrauterine injection of PGE-1 $(0 \cdot 2-0 \cdot 4 \mu \mathrm{g} /$ hen $)$ to 12 hens pretreated with $25 \mathrm{mg}$ indomethacin induced oviposition in all birds in about $7 \frac{1}{2} \mathrm{~min}$. Passive immunization with goat antiserum to PGE-1 delayed oviposition $(69 \%)$ in 4 hens. It is concluded that prostaglandins play a functional role in oviposition.
\end{abstract}

\section{Introduction}

The physiological role of prostaglandins (PGs) in mammalian reproduction has been studied extensively in recent years (Speroff \& Ramwell, 1970; Csapo, 1973; Labhsetwar, 1974; Pharriss \& Shaw, 1974; Behrman, Rahway \& Anderson, 1974; Cenedella, 1975; Craig, 1975; Goldberg \& Ramwell, 1975). Little is known, however, of the possible function of these potent biological substances in the reproductive activity of birds, although it has been shown that PGs, particularly of the E series, are potent oxytocic compounds which, when injected at submicrogram quantities into the avian uterus (shell gland), can induce premature oviposition within a few minutes (Hertelendy, 1972; Hertelendy, Yeh \& Biellier, 1974; Verma, Prasad \& Slaughter, 1976). Furthermore, the essential fatty acids (linoleic and arachidonic), which are known to serve as precursors of PG biosynthesis, provoke a similar response. Administration of inhibitors of PG synthesis blocks the premature, as well as spontaneous, oviposition (Hertelendy, 1973; Day \& Nalbandov, 1978) and inhibits the response to oxytocin which has been implicated in the regulation of oviposition (Tanaka \& Nakajo, 1962). Significantly higher plasma levels of PGE have been observed when there was an egg in the uterus compared to values shortly after oviposition (Hertelendy \& Biellier, 1978) and Day \& Nalbandov (1977) demonstrated a dramatic increase in PGF content of the postovulatory follicle shortly before oviposition. These and other observations suggest that PGs may play a physiological role in oviposition. We now present further evidence in support of this suggestion.

\section{Materials and Methods}

High egg-producing white Leghorn hens (Gallus domesticus) were caged singly in a 16-h light/8-h dark photoperiod and had free access to a pelleted laying ration and water. Under these conditions, the hens laid almost daily with $23-27 \mathrm{~h}$ between eggs. An accurate laying record was kept by means of an electronic device that scanned the cages every $15 \mathrm{~min}$, recording the presence of a freshly laid egg.

In Exp. 1, 33 hens were given orally a single capsule of $25 \mathrm{mg}$ indomethacin (Indocin: Merck) 2-4 $\mathrm{h}$ before the expected time of oviposition (the presence of a hard egg in the uterus being confirmed by palpation), and 10 control birds were given a similar amount of lactose.

In Exp. 2, 20 hens were similarly treated with indomethacin $2-4 \mathrm{~h}$ before expected oviposition, and 1-3 $\mathrm{h}$ after the expected oviposition 12 of the birds were given an intrauterine injection of $0 \cdot 15 \mu \mathrm{g}$ PGE-1/kg, diluted from an ethanolic stock solution in $0.15 \mathrm{M}-\mathrm{NaCl}$. The other 8 birds received $0.5 \mathrm{ml}$ $0 \cdot 15 \mathrm{M}-\mathrm{NaCl}$, and blood samples were withdrawn from them before and 4-5 h after the indomethacin treatment. 
The blood samples were collected into heparinized plastic syringes and immediately transferred into chilled plastic tubes for centrifugation at $2000 \mathrm{~g}$ for $10 \mathrm{~min}$. The plasma was removed and kept frozen until extraction for analysis of PGE $(1+2)$ by the radioimmunoassay described by Hertelendy \& Biellier (1978). The antiserum to PGE was raised in goats against a PGE-1-BSA conjugate as described previously (Hertelendy \& Biellier, 1978). The calculated binding capacity, as defined by Csapo, Dray \& Erdos (1975), of the particular antiserum used in this study was about $1.5 \mu \mathrm{g} / \mathrm{ml}$. With the exception of PGE-2 with which it exhibited a $52 \%$ cross-reactivity, the antiserum had a good specificity $(<1 \%$ cross-reaction) against a number of prostaglandins including PGF- $2 \alpha$. The sensitivity of the assay was $10 \mathrm{pg} /$ tube and the recovery after chromatography was $69 \pm 5 \cdot 8$ (s.e.m.) $\%$ $(61-83 \%)$. The coefficients of variation within and between assays were $9.3 \%(n=8)$ and $16.5 \%$ $(n=11)$ for plasma with low PGE concentrations (young cockerels) and $11 \%(n=6)$ and $14.3 \%$ ( $n=11$ ) for high concentrations (laying hens).

In Exp. 3, 4 laying hens were passively immunized to PGE by an intraperitoneal injection of $1.3-1.5 \mathrm{ml}$ antiserum to PGE (undiluted) and 5 control hens received the same volume of normal goat serum. All injections were given 2-3 h before expected oviposition.

\section{Results}

\section{Inhibition of oviposition by indomethacin}

Of the 33 hens treated with indomethacin in Exp. 1, 31 exhibited a delay of oviposition, while lactose had no effect (Table 1).

Table 1. The effect of indomethacin on the time (mean \pm s.e.m.) of oviposition in the hen

\begin{tabular}{|c|c|c|c|c|c|}
\hline \multirow[b]{2}{*}{ Treatment } & \multirow{2}{*}{$\begin{array}{l}\text { No. of } \\
\text { birds }\end{array}$} & \multicolumn{3}{|c|}{ Time between eggs $(h) \dagger$} & \multirow{2}{*}{$\begin{array}{c}\text { Delay of } \\
\text { oviposition }(h)\end{array}$} \\
\hline & & -2 & -1 & +1 & \\
\hline Indomethacin (25 mg) & 33 & $23.52 \pm 0.21$ & $23.90 \pm 0.18$ & $35.69 \pm 0.73^{*}$ & $11.81 \pm 0.74$ \\
\hline Control (lactose, $25 \mathrm{mg}$ ) & 10 & $24.03 \pm 0.16$ & $23.92 \pm 0.12$ & $23.94 \pm 0.13^{*}$ & 0 \\
\hline
\end{tabular}

* These values are significantly different $(P<0.001$ by Student's $t$ test).

$\dagger$ The -2 and -1 represent the last two eggs before treatment, +1 the first egg after treatment.

Table 2. The effect of passive immunization against PGE on the time of oviposition in hens

\begin{tabular}{|c|c|c|c|c|c|}
\hline \multirow{2}{*}{$\begin{array}{l}\text { Bird } \\
\text { No. }\end{array}$} & \multirow[b]{2}{*}{ Treatment } & \multicolumn{2}{|c|}{ Time between eggs (h) } & \multirow{2}{*}{$\begin{array}{l}\text { Delay of } \\
\text { oviposition } \\
\text { (h) }\end{array}$} & \multirow[b]{2}{*}{$\%$} \\
\hline & & Before* & After $\dagger$ & & \\
\hline 6 & A-PGE & 25 & 41 & 16 & 64 \\
\hline 20 & A-PGE & 25 & 51 & 26 & 104 \\
\hline 116 & A-PGE & $24 \cdot 5$ & 39 & $14 \cdot 5$ & 59 \\
\hline 178 & A-PGE & 27 & 40 & 13 & 48 \\
\hline Mean & & $25 \cdot 4$ & $42 \cdot 8 \ddagger$ & $17 \cdot 4$ & 69 \\
\hline 205 & NGS & $24 \cdot 5$ & $26 \cdot 5$ & 2 & 8 \\
\hline 307 & NGS & $26 \cdot 5$ & $26 \cdot 5$ & 0 & 0 \\
\hline 53 & NGS & $25 \cdot 25$ & $25 \cdot 5$ & 0 & 0 \\
\hline 151 & NGS & $25 \cdot 25$ & $27 \cdot 0$ & 1.75 & 7 \\
\hline 229 & NGS & $24 \cdot 25$ & $24 \cdot 5$ & 0 & 0 \\
\hline Mean & & $25 \cdot 15$ & $26 \cdot 0$ & 0.85 & 3 \\
\hline
\end{tabular}

A-PGE, antiserum to PGE; NGS, normal goat serum.

* Before $=$ interval between the last 2 eggs before treatment.

$\dagger$ After $=$ interval between last egg before treatment and first egg after treatment.

$\ddagger$ Significantly different from 'Before' $(P<0.001$ by paired $t$ test). 
In Exp. 2, oviposition was again delayed by the indomethacin treatment, but the PGE-1 injection induced oviposition in all 12 birds in $7.5 \pm 0.8$ (s.e.m.) min (range 3-13 min). The other 8 birds did not lay until $9 \cdot 4 \pm 1 \cdot 2 \mathrm{~h}$ after the saline injection, i.e. $10 \cdot 8 \pm 1.0 \mathrm{~h}$ after expected oviposition. In these 8 hens there was, associated with the delay of oviposition, a significant $(P<0.001$ by paired $t$-test) drop in plasma PGE concentrations from $0.82 \pm 0.16 \mathrm{ng} / \mathrm{ml}$ before to $0.1 \pm 0.03 \mathrm{ng} / \mathrm{ml}$ at $4-5 \mathrm{~h}$ after the indomethacin treatment.

\section{Inhibition of oviposition by antiserum to PGE}

The results of Exp. 3 clearly demonstrate that antiserum to PGE was at least as effective in blocking oviposition as $25 \mathrm{mg}$ indomethacin, whereas the same volume of normal goat serum had no effect (Table 2).

\section{Discussion}

Previous studies have shown that administration of prostaglandins, particularly of the E series, can predictably induce premature oviposition in the hen (Hertelendy et al., 1974; Verma et al., 1976). The present experiments, showing that indomethacin effectively delayed spontaneous oviposition and that this effect coincided with a dramatic drop in plasma levels of PGE, provide strong evidence for a functional role for endogenous prostaglandins in the regulation of oviposition. One may, however, regard experimental evidence based on indomethacin-provoked responses as indirect and equivocal, in view of the effects of indomethacin that appear to be independent of prostaglandin synthesis (Northover, 1971, 1972, 1973). However, the ability of a low dose of PGE-1 to overcome the indomethacin block, and the successful delay of oviposition by passive immunization against PGE, provide direct evidence for the participation of prostaglandins in oviposition.

While these studies demonstrate that PGE plays a functional role in oviposition, its mode of action on the avian uterus remains obscure. Day \& Nalbandov (1977) suggested that PGF originating in the postovulatory follicle controls the time of oviposition. Several authors have reported that prostaglandins affect oviductal motility in the hen (Wechsung \& Houvenaghel, 1975, 1976; Verma et al., 1976), and it has been suggested that prostaglandins may play an autoregulatory role in the transport of the egg through the tubal portion of the female reproductive tract (Talo \& Kekäläinen, 1976). Experiments designed to clarify further the role of prostaglandins in avian reproduction are in progress.

This work was supported by USPH grant HD 09763 and by a grant from the Wallace Genetic Foundation. We are indebted to Dr J. Pike, The Upjohn Company, for the supply of PGE-1.

\section{References}

Behrman, H.R., Rahway, N.J. \& Anderson, G.G. (1974) Prostaglandins in reproduction. Arch. intern. Med. 133, 77-84.

Cenedella, R.J. (1975) Prostaglandins and male reproductive physiology. Adv. Sex Horm. Res. 1, 325-358.

CralG, G.M. (1975) Prostaglandins in reproductive physiology. Postgrad. Med.J. 51, 74-84.

CSAPo, A.I. (1973) The regulatory interplay of progesterone and prostaglandin $F_{2 a}$ in the control of the pregnant uterus. In Uterine Contraction-Side Effects of Steroidal Contraceptives, pp. 223-255. Ed. J. B. Josimovich. John Wiley \& Sons, New York.

Csapo, A.I., Dray, F. \& Erdos, T. (1975) The biological effects of injected antibodies to estradiol-17 $\beta$ and to progesterone in pregnant rats. Endocrinology 97, 603-614.

Day, S.L. \& Nalbandov, A.V. (1977) Presence of prostaglandin F (PGF) in hen follicles and its physiological role in ovulation and oviposition. Biol. Reprod. 16, 486-494.

Goldberg, V.J. \& Ramwell, P.W. (1975) Role of prostaglandins in reproduction. Physiol. Rev. 55, 325-351.

Hertelendy, F. (1972) Prostaglandin-induced premature oviposition in the coturnix quail. Prostaglandins 2, 269-279.

HeRTELeNdy, F. (1973) Block of oxytocin-induced parturition and oviposition by prostaglandin inhibitors. Life Sciences 13, 1581-5189. 
Hertelendy, F. \& Biellier, H.V. (1978) Prostaglandin levels in avian blood and reproductive organs. Biol. Reprod. (in press).

Hertelendy, F., Yeh, M. \& Biellier, H.V. (1974) Induction of oviposition in the domestic hen by prostaglandins. Gen. comp. Endocr. 22, 529-531.

Labhsetwar, A.P. (1974) Prostaglandins and the reproductive cycle. Fedn Proc. Fedn Am. Socs exp. Biol. 33, 61-77.

NORTHOVER, B.J. (1971) Mechanism of the inhibitory action of indomethacin on smooth muscle. Br. J. Pharmac. 41, 540-551.

NoRTHOVER, B.J. (1972) The effects of indomethacin on calcium, sodium, potassium and magnesium fluxes in various tissues of the guinea-pig. $B r . J$. Pharmac. 45, 651-659.

Northover, B.J. (1973) Effect of anti-inflammatory drugs on the binding of calcium to cellular membranes in various human and guinea-pig tissues. $\mathrm{Br}$. J. Pharmac. 48, 496-504.
Pharriss, B.B. \& Shaw, J.E. (1974) Prostaglandins in reproduction. A. Rev. Physiol. 36, 391-412.

Speroff, L. \& Ramwell, P.W. (1970) Prostaglandins in reproductive physiology. Am. J. Obstet. Gynec. 107, 1111-1130.

TAlo, A. \& KeKÄLÄInen, R. (1976) Ovum promotes its own transport in the oviduct of the Japanese quail. Biol. Reprod. 14, 186-189.

Tanaka, K. \& Nakajo, S. (1962) Participation of neurohypophyseal hormones in oviposition in the hen. Endocrinology 70, 453-458.

Verma, O.P., Prasad, B.K. \& Slaughter, J. (1976) Avian oviduct motility induced by prostaglandin E-1. Prostaglandins 12, 217-227.

Wechsung, E. \& Houvenaghel, A. (1975) The effect of prostaglandins on pressure in the chicken oviduct. Arch. int. Pharmacodyn. Ther. 217, 173-174.

Wechsung, E. \& Houvenaghel, A. (1976) A possible role of prostaglandins in the regulation of ovum transport and oviposition in the domestic hen. Prostaglandins 12, 599-608.

Received 25 August 1977 